\title{
An allocation Malmquist index with an application in the China securities industry
}

\author{
Nan Zhu \\ Western Business School, \\ Southwestern University of Finance and Economics, \\ Chengdu 610074, \\ China

\section{Yi Liu} \\ School of Business Administration, \\ Southwestern University of Finance and Economics, \\ Chengdu 610074, \\ China
}

\section{Ali Emrouznejad}

\author{
Professor of Business Analytics \\ Aston Business School, \\ Aston University, \\ Birmingham, \\ UK \\ a.emrouznejad@aston.ac.uk

\section{Qiang Huang} \\ School of Business Administration, \\ Southwestern University of Finance and Economics, \\ Chengdu 610074, \\ China
}

\section{Acknowledgements}

This work is financially supported by 211 Project for the Southwestern University of Finance and Economics (Phase 3), Chengdu, China. The authors would like to thank Mr. Guangdong Sun and Miss Jing He for assistant work of collecting the data. We also would like to thank to anonymous reviewers for their insightful comments and suggestions, as results the paper has been improved substantially. 


\title{
An allocation Malmquist index with an application in the China securities industry
}

\begin{abstract}
:
This paper proposes an allocation Malmquist index which is inspired by the work on the non-parametric cost Malmquist index. We first show that how to decompose the cost Malmquist index into the input-oriented Malmquist index and the allocation Malmquist index. An application in corporate management of the China securities industry with the panel data set of 40 securities companies during the period 2005-2011 shows the practicality of the propose model.
\end{abstract}

Keywords: Data Envelopment Analysis; Overall efficiency; Allocative efficiency; Allocation Malmquist index.

\section{Introduction}

Since Charnes et al. (1978) introduced Data Envelopment Analysis (DEA) as a non-parametric model for measuring the efficiency of Decision Making Units (DMUs) more than 5000 studies have been reported in this area (Emrouznejad, et al., 2008 \& Emrouznejad and De Witte, 2010). Non-parametric Malmquist index is also introduced by Färe et al. (1994) (see also Malmquist (1953) and Caves et al. (1982)). As results many theoretical studies as well as applications in productivity measurement are reported in the literature.

Maniadakis and Thanassoulis (2004) have developed a cost Malmquist index (CM) applicable when decision-makers can be assumed to be cost minimizers and input-output quantity and input price data are known. They have pointed out that the CM index can be decomposed as follows:

$$
\begin{aligned}
\mathrm{CM} & =\mathrm{OEC} \times \mathrm{CTC} \\
& =\mathrm{TEC} \times \mathrm{AEC} \times \mathrm{TC} \times \mathrm{PE} \\
& =\mathrm{IM} \times \mathrm{AEC} \times \mathrm{PE}
\end{aligned}
$$




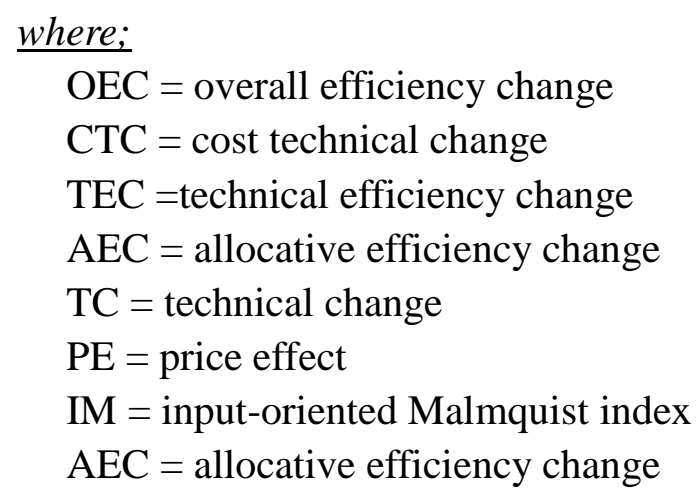

In this paper, following the study of Maniadakis and Thanassoulis (2004), a concept of an Allocation Malmquist index (AM) is proposed and three types of Malmquist indexes with their relationships in the framework of organization management are discussed. The cost Malmquist index can be decomposed into the input-oriented Malmquist index and the allocation Malmquist index. To show the applicability of the proposed model, the productivity measure in corporate management of the China securities industry, with the panel data set of 40 securities companies during the period 2005-2011, is provided and discussed. Note that the efficiencies and productivities given in this paper are calculated in the input-oriented measure; with the same manner output-oriented measures can be also defined.

There are only a few papers using DEA to study the efficiency and productivity problems of securities companies which, in fact, plays an important role in the capital market. For examples, Goldberg et al. (1991), Zhang et al. (2006), Fukuyama and Weber (2008), Zhu and Liu (2008) used DEA method, respectively, to discuss the efficiency and productivity problems of securities companies of some countries including US, Japan and China.

Zhang et al. (2006) studied the technical efficiency and classical Malmquist index of the US securities companies. They pointed out that the lack of research in the securities industry can be attributed mainly to industry regulators as they have not collected / published information used for analyzing the securities industry. To the best of our knowledge there is no single studying on the overall efficiency and CM of the China securities companies. 
The rest of the paper is organized as follows. The methodology is discussed in Section 2. In this section we also introduce the concept of Allocation Malmquist Index and its decomposition. Section 3 presents an application in the China securities industry by using the propose model and Section 4 concludes this paper and provides direction for future research.

\section{Methodology}

\subsection{Technical efficiency, overall efficiency and allocative efficiency}

Consider a set of $J$ decision-making units (DMUs) with $n$ input and $m$ output in T $(t=1, \ldots \mathrm{T})$ periods. Assume in time period $t$, decision-makers are using inputs $x^{t} \in R_{+}^{n}$, to produce outputs $y^{t} \in R_{+}^{m}$. Figure 1 provides an illustration of an input-distance function in period t, where two inputs, $x_{1}{ }^{t}$ and $x_{2}{ }^{t}$, are used to produce output, $y^{t}$. The isoquant, SS', is the inner boundary of the input set reflecting the minimum input combinations that may be used to produce a given output vector in period $t$. In this case, the value of the distance function for a firm producing output, $y^{t}$, using the input vector defined by point $\mathrm{A}$, is equal to the ratio, $\mathrm{OA} / \mathrm{OB}$.

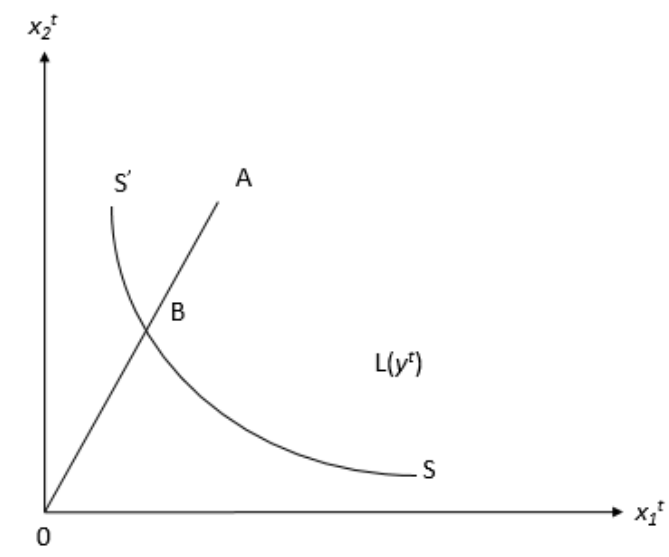

Figure 1. Input isoquant and input distance function

Consider the input distance function $D^{t}\left(y^{t}, x^{t}\right)$ of period $t$, the technical (or productive) efficiency (TE) in period $t$ is defined as :

$$
\left.\mathrm{TE}\left(y^{t}, x\right)=1 D^{t} y^{t}\right) x
$$


In general, $\mathrm{TE}<1$, indicates that the DMU under assessment, comparing with other DMUs, is productively inefficient since its production is based on excessive input usage. TE $=1$, indicates the DMU is fully productively efficient.

As Maniadakis and Thanassoulis (2004), given input prices $w^{t} \in R_{+}^{n}$, lets also consider the cost function $C^{t}\left(y^{t}, w^{t}\right)$ that represents the minimum cost of production of period $t$, the following formula represents the overall (or cost) efficiency (OE) in period $t$ for $\left(y^{t}, x^{t}\right)$ under input prices $w^{t}$ :

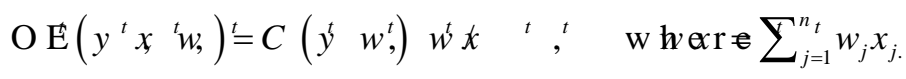

In general, $\mathrm{OE}<1$, indicates that the DMU under assessment, comparing with other DMUs, is cost inefficient. $\mathrm{OE}=1$ indicates that the DMU is fully cost efficient.

Using above input distance and cost functions, allocative efficiency (AE) in period $t$ for $\left(y^{t}, x^{t}\right)$ under input prices $w^{t}$ is defined as follows:

$$
\mathrm{AE}^{t}\left(y^{t}, x^{t}, w^{t}\right)=D^{t}\left(y^{t}, x^{t}\right) \times C^{t}\left(y^{t}, w^{t}\right) / w^{t} x^{t}
$$

The AE reflects the distance between the actual and minimum cost at which a DMU may secure its outputs once any productive inefficiency of the DMU has been eliminated. In general, $\mathrm{AE}<1$ indicates that the DMU under assessment comparing with other DMUs, is allocatively inefficient, since its production takes place at the wrong input mix in light of input prices. $\mathrm{AE}=1$ indicates the $\mathrm{DMU}$, comparing with other DMUs, is fully allocatively efficient.

According to Farrell (1957) the OE can be decomposed into the TE and AE (see also Cooper, Seiford and Tone, 2000):

$$
\mathrm{OE}^{t}\left(y^{t}, x^{t}, w^{t}\right)=\operatorname{TE}^{t}\left(y^{t}, x^{t}\right) \times \mathrm{AE}^{t}\left(y^{t}, x^{t}, w^{t}\right) .
$$

Accordingly, if a DMU is cost inefficient, it is either productively inefficient or allocatively inefficient, or both. In other words, it is either because production is 
based on excessive input usage or because it takes place at the wrong input mix in light of input prices, or both (Maniadakis and Thanassoulis, 2004).

\subsection{Three types of Malmquist indexes}

\subsubsection{Input-oriented (production) Malmquist index}

Let $\mathrm{IM}^{t}$ and $\mathrm{IM}^{t+1}$, measures the distance of $\left(y^{t+1}, x^{t+1}\right)$ and $\left(y^{t}, x^{t}\right)$ from the Constant Returns to Scale (CRS) production boundary of period $t, t+1$, respectively. We have

$$
\operatorname{IM}^{t}=\frac{D^{t}\left(y^{t+1}, x^{t+1}\right)}{D^{t}\left(y^{t}, x^{t}\right)}, \quad \operatorname{IM}^{t+1}=\frac{D^{t+1}\left(y^{t+1}, x^{t+1}\right)}{D^{t+1}\left(y^{t}, x^{t}\right)}
$$

where $\mathrm{IM}^{t}$ and $\mathrm{IM}^{t+1}$ are called the input-oriented Malmquist index (IM) of period $t$, $t+1$, respectively (Maniadakis and Thanassoulis, 2004). The IM of period $t, t+1$ is defined by the geometric mean of $\mathrm{IM}^{t}$ and $\mathrm{IM}^{t+1}$, see (7). It is well known that the IM can be decomposed into the technical (or productive) efficiency change (TEC or PEC) and (production-) technical change (TC or PTC) as follows:

$$
\begin{aligned}
\mathrm{IM} & =\left[\mathrm{IM}^{t} \times \mathrm{IM}^{t+1}\right]^{1 / 2} \\
& =\frac{\operatorname{TE}^{t}\left(y^{t}, x^{t}\right)}{\operatorname{TE}^{t+1}\left(y^{t+1}, x^{t+1}\right)} \times\left[\frac{D^{t}\left(y^{t}, x^{t}\right)}{D^{t+1}\left(y^{t}, x^{t}\right)} \times \frac{D^{t}\left(y^{t+1}, x^{t+1}\right)}{D^{t+1}\left(y^{t+1}, x^{t+1}\right)}\right]^{1 / 2} \\
& =\mathrm{TEC} \times \mathrm{TC},
\end{aligned}
$$

where $\mathrm{TEC}=\mathrm{TE}^{t}\left(y^{t}, x^{t}\right) / \mathrm{TE}^{t+1}\left(y^{t+1}, x^{t+1}\right)$ denotes the change of the technical efficiency between period $t$ and $t+1$. The TEC indicates whether the DMU 'catches up' the production boundary when moving from period $t$ to $t+1$. In this case TEC $<1$, TEC $>$ 1 and TEC $=1$ imply the technical efficiency, respectively, increase, decrease and constant between period $t$ and $t+1$. The TEC can be further decomposed into the scale efficiency change (SEC) and pure technical efficiency change (PTEC): TEC $=$ SEC $\times$ PTEC (Färe et al. 1996, and Ray and Desli, 1997).

In (5), the TC denotes the technical change of the DMU between period $t$ and $t+1$ that 
measures the shift of the production boundary evaluated at the inputs $x^{t}$ and $x^{t+1}$. The progress and regress in production technology between period $t$ and $t+1$ can be identified by $\mathrm{TC}<1$ and $\mathrm{TC}>1$, respectively. Similarly, $\mathrm{IM}<1$ (IM $>1)$ implies the input-oriented Malmquist index progress (regress) between period $t$ and $t+1$.

IM is applicable when decision-makers are making production management and input-output quantity data are known. Hence, the IM index, as the classical Malmquist index of Färe et al. (1994), is directly concerning to production and can be considered as a production Malmquist index (PM).

\subsubsection{Cost Malmquist index}

In the DEA literature, the non-parametric cost Malmquist indices, $\mathrm{CM}^{t}$ and $\mathrm{CM}^{t+1}$ of period $t, t+1$ are defined as follows (Maniadakis and Thanassoulis, 2004):

$$
\mathrm{CM}^{t}=\frac{w^{t} x^{t+1} / C^{t}\left(y^{t+1}, w^{t}\right)}{w^{t} x^{t} / C^{t}\left(y^{t}, w^{t}\right)}, \quad \mathrm{CM}^{t+1}=\frac{w^{t+1} x^{t+1} / C^{t+}\left(y^{t+1}, w^{t+}\right)}{w^{t+1} x^{t} / C^{t+1}\left(y^{t}, w^{t+}\right)}
$$

The cost Malmquist index of period $t, t+1(\mathrm{CM})$ is defined by the geometric mean of $\mathrm{CM}^{t}$ and $\mathrm{CM}^{t+1}$, see (9). Using (3), we have:

$$
\begin{aligned}
\mathrm{CM} & =\left[\mathrm{CM}^{t} \times \mathrm{CM}^{t+1}\right]^{1 / 2}=\left[\frac{w^{t} x^{t+1} / C^{t}\left(y^{t+1}, w^{t}\right)}{w^{t} x^{t} / C^{t}\left(y^{t}, w^{t}\right)} \times \frac{w^{t+1} x^{t+1} / C^{t+1}\left(y^{t+1}, w^{t+1}\right)}{w^{t+1} x^{t} / C^{t+1}\left(y^{t}, w^{t+1}\right)}\right]^{1 / 2} \\
& =\frac{w^{t+1} x^{t+1} / C^{t+1}\left(y^{t+1}, w^{t+1}\right)}{w^{t} x^{t} / C^{t}\left(y^{t}, w^{t}\right)} \times\left[\frac{w^{t} x^{t} / C^{t}\left(y^{t}, w^{t}\right)}{w^{t+1} x^{t} / C^{t+1}\left(y^{t}, w^{t+1}\right)} \times \frac{w^{t} x^{t+1} / C^{t}\left(y^{t+1}, w^{t}\right)}{w^{t+1} x^{t+1} / C^{t+1}\left(y^{t+1}, w^{t+1}\right)}\right]^{1 / 2} \\
& =\frac{\mathrm{OE}^{t}\left(y^{t}, x^{t}, w^{t}\right)}{\mathrm{OE}^{t+1}\left(y^{t+1}, x^{t+1}, w^{t+1}\right)} \times\left[\frac{w^{t} x^{t} / C^{t}\left(y^{t}, w^{t}\right)}{w^{t+1} x^{t} / C^{t+1}\left(y^{t}, w^{t+1}\right)} \times \frac{w^{t} x^{t+1} / C^{t}\left(y^{t+1}, w^{t}\right)}{w^{t+1} x^{t+1} / C^{t+1}\left(y^{t+1}, w^{t+1}\right)}\right]^{1 / 2} \\
& =\mathrm{OEC} \times \mathrm{CTC} .
\end{aligned}
$$

The CM index is applicable when decision-makers are making cost management and input-output quantity and input price data are known. Similar to decomposition of the IM index of (7), the CM can be decomposed into the overall (or cost) efficiency change (OEC or CEC) and cost-technical change (CTC), see (9).

$\mathrm{OEC}=\mathrm{OE}^{t}\left(y^{t}, x^{t}, w^{t}\right) / \mathrm{OE}^{t+1}\left(y^{t+1}, x^{t+1}, w^{t+1}\right)$ denotes the change of the overall efficiency 
between period $t$ and $t+1$. The OEC indicates whether the DMU 'catches up' the cost boundary when moving from period $t$ to $t+1$. OEC $<1$, OEC $>1$ and OEC $=1$ imply the overall efficiency, respectively, increase, decrease and constant between period $t$ and $t+1$. Similar concept is applied to CTC that measures the shift of the cost boundary evaluated at the input prices $w^{t}$ and $w^{t+1}$. Also the progress or regress in the cost Malmquist index between period $t$ and $t+1$ can be identified by $\mathrm{CM}<1$ or $\mathrm{CM}<1$, respectively.

\subsubsection{Allocation Malmquist index}

In the spirit of the work done by Farrell (1957), Färe et al. (1994) and Maniadakis and Thanassoulis (2004), the $\mathrm{AM}^{t}$ and $\mathrm{AM}^{t+1}$ are called the allocation Malmquist index of period $t, t+1$, respectively, can be defined as follows:

$$
\begin{aligned}
& \mathrm{AM}^{t}=\frac{w^{t} x^{t+1} / C^{t}\left(y^{t+1}, w^{t}\right) D^{t}\left(y^{t+1}, x^{t+1}\right)}{w^{t} x^{t} / C^{t}\left(y^{t}, w^{t}\right) D^{t}\left(y^{t}, x^{t}\right)} \\
& \mathrm{AM}^{t+1}=\frac{w^{t+1} x^{t+1} / C^{t+1}\left(y^{t+1}, w^{t+1}\right) D^{t+1}\left(y^{t+1}, x^{t+1}\right)}{w^{t+1} x^{t} / C^{t+1}\left(y^{t}, w^{t+1}\right) D^{t+1}\left(y^{t}, x^{t}\right)} .
\end{aligned}
$$

The overall allocation Malmquist index of period $t$ to period $t+1$ (AM), using the geometric mean of $\mathrm{AM}^{t}$ and $\mathrm{AM}^{t+1}$ can be decomposed as follows:

$$
\begin{aligned}
\mathrm{AM} & =\left[\mathrm{AM}^{t} \times \mathrm{AM}^{t+1}\right]^{1 / 2} \\
& =\left[\frac{w^{t} x^{t+1} / C^{t}\left(y^{t+1}, w^{t}\right) D^{t}\left(y^{t+1}, x^{t+1}\right)}{w^{t} x^{t} / C^{t}\left(y^{t}, w^{t}\right) D^{t}\left(y^{t}, x^{t}\right)} \times \frac{w^{t+1} x^{t+1} / C^{t+1}\left(y^{t+1}, w^{t+1}\right) D^{t+1}\left(y^{t+1}, x^{t+1}\right)}{w^{t+1} x^{t} / C^{t+1}\left(y^{t}, w^{t+1}\right) D^{t+1}\left(y^{t}, x^{t}\right)}\right]^{1 / 2} \\
& =\frac{w^{t+1} x^{t+1} / C^{t+1}\left(y^{t+1}, w^{t+1}\right) D^{t+1}\left(y^{t+1}, x^{t+1}\right)}{w^{t} x^{t} / C^{t}\left(y^{t}, w^{t}\right) D^{t}\left(y^{t}, x^{t}\right)} \times \\
& {\left[\frac{w^{t} x^{t} / C^{t}\left(y^{t}, w^{t}\right) D^{t}\left(y^{t}, x^{t}\right)}{w^{t+1} x^{t} / C^{t+1}\left(y^{t}, w^{t+1}\right) D^{t+1}\left(y^{t}, x^{t}\right)} \times \frac{w^{t} x^{t+1} / C^{t}\left(y^{t+1}, w^{t}\right) D^{t}\left(y^{t+1}, x^{t+1}\right)}{w^{t+1} x^{t+1} / C^{t+1}\left(y^{t+1}, w^{t+1}\right) D^{t+1}\left(y^{t+1}, x^{t+1}\right)}\right]^{1 / 2} }
\end{aligned}
$$




$$
\begin{aligned}
= & \frac{\operatorname{AE}^{t}\left(y^{t}, x^{t}, w^{t}\right)}{\operatorname{AE}^{t+1}\left(y^{t+1}, x^{t+1}, w^{t+1}\right)} \times \\
& {\left[\frac{w^{t} x^{t} / C^{t}\left(y^{t}, w^{t}\right) D^{t}\left(y^{t}, x^{t}\right)}{w^{t+1} x^{t} / C^{t+1}\left(y^{t}, w^{t+1}\right) D^{t+1}\left(y^{t}, x^{t}\right)} \times \frac{w^{t} x^{t+1} / C^{t}\left(y^{t+1}, w^{t}\right) D^{t}\left(y^{t+1}, x^{t+1}\right)}{w^{t+1} x^{t+1} / C^{t+1}\left(y^{t+1}, w^{t+1}\right) D^{t+1}\left(y^{t+1}, x^{t+1}\right)}\right]^{1 / 2} } \\
= & \mathrm{AEC} \times \mathrm{ATC} .
\end{aligned}
$$

Similar to the CM index, the AM index is applicable when decision-makers are making resource allocation management and the input-output quantity and input price data are known. From (11), it can be seen that similar to the IM of (7) and CM of (9), the AM can be decomposed into the allocative efficiency change (AEC) and allocation-technical change (ATC) *

$\mathrm{AEC}=\mathrm{AE}^{t}\left(y^{t}, x^{t}, w^{t}\right) / \mathrm{AE}^{t+1}\left(y^{t+1}, x^{t+1}, w^{t+1}\right)$ that denotes the change of the allocative efficiency between period $t$ and $t+1$. The AEC indicates whether the production boundary of the DMU 'catches up' the cost boundary when going from period $t$ to $t+1$.

In (10), the ATC denotes the change of allocation technology of the DMU between period $t$ and $t+1$ that measures the shift of the production boundary evaluated at the inputs $x^{t}$ and $x^{t+1}$ and cost boundary evaluated at the input prices $w^{t}$ and $w^{t+1}$.

Just as with the $\mathrm{IM}$ and $\mathrm{CM}$ indexes, $\mathrm{AM}<1, \mathrm{AM}>1$ and $\mathrm{AM}=1$ imply the allocation Malmquist index, respectively, progress, regress and constant between period $t$ and $t+1$.

\subsubsection{Geometric meaning of IM, CM and AM}

The IM, CM and AM and their component indexes are illustrated in Figure $2^{\dagger}$. As in Maniadakis and Thanassoulis (2004), there is a case where production takes place

\footnotetext{
* The term of 'allocation-technical change (ATC)' in this paper was called the term of 'price effect (PE)' by Maniadakis and Thanassoulis (2004). It was also discussed, and a suggestion that 'one may view this term as AEC at industry rather than at firm level' was provided by Maniadakis and Thanassoulis (2004).

$\dagger$ The wrong printing of $w^{t} x^{t+1}$ and $w^{t+1} x^{t+1}$ in Fig. 2 given by Maniadakis and Thanassoulis (2004) are revised in Fig. 1 of this paper.
} 
under CRS and two inputs, $\left(x_{1}, x_{2}\right) \in R_{+}^{2}$, are used to produce single output, $y \in R_{+}$. Production takes place at point $\mathrm{G}:\left(y^{t}, x^{t}\right)$ in period $t$ and shifts to point $\mathrm{B}:\left(y^{t+1}, x^{t+1}\right)$ in period $t+1$. The outputs in both periods are standardized to one unit and so $y^{t}=y^{t+1}$. Isoq $L^{t}\left(y^{t}\right)$ and $\operatorname{Iso} C^{t}\left(y^{t}, w^{t}\right)$ are the input isoquant and isocost lines in period $t$, respectively. Here, the cost boundary Iso $C^{t}\left(y^{t}, w^{t}\right)$ contains the input vectors that are capable of securing output $y^{t}$ at the cost of $C^{t}\left(y^{t}, w^{t}\right)$. We have:

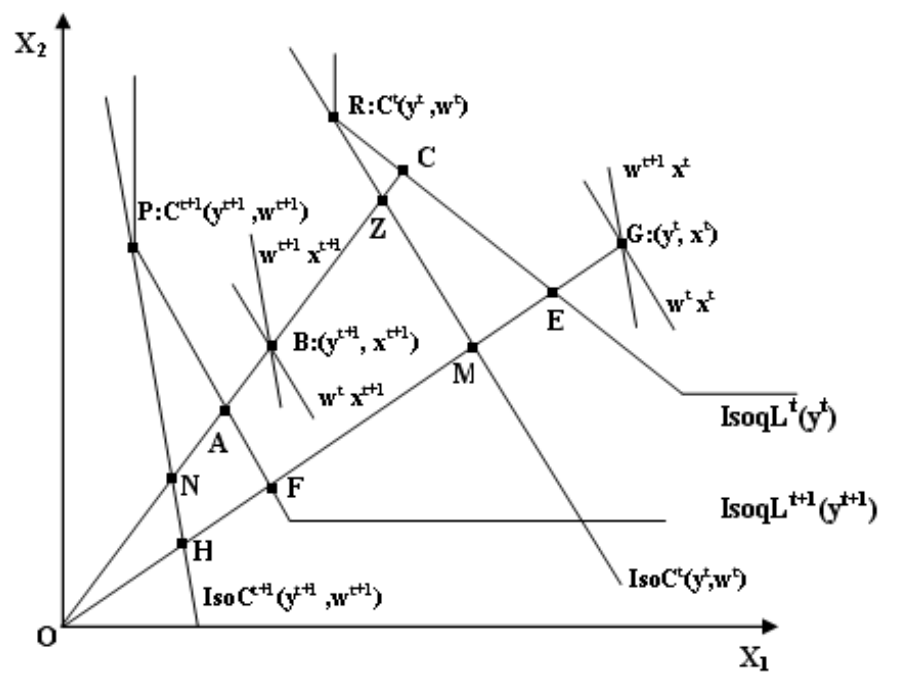

Figure 2. The input-oriented (production), cost and allocation Malmquist indexes

The decomposition of IM can be presented as follows:

$$
\begin{aligned}
\mathrm{IM} & =\left[\frac{\mathrm{OB} / \mathrm{OC}}{\mathrm{OG} / \mathrm{OE}} \times \frac{\mathrm{OB} / \mathrm{OA}}{\mathrm{OG} / \mathrm{OF}}\right]^{1 / 2}=\frac{\mathrm{OB} / \mathrm{OA}}{\mathrm{OG} / \mathrm{OE}} \times\left[\frac{\mathrm{OG} / \mathrm{OE}}{\mathrm{OG} / \mathrm{OF}} \times \frac{\mathrm{OB} / \mathrm{OC}}{\mathrm{OB} / \mathrm{OA}}\right]^{1 / 2} \\
& =\frac{\mathrm{OE} / \mathrm{OG}}{\mathrm{OA} / \mathrm{OB}} \times\left[\frac{\mathrm{OF}}{\mathrm{OE}} \times \frac{\mathrm{OA}}{\mathrm{OC}}\right]^{1 / 2}=\mathrm{TEC} \times \mathrm{TC} ; \\
\mathrm{CM} & =\left[\frac{\mathrm{OB} / \mathrm{OZ}}{\mathrm{OG} / \mathrm{OM}} \times \frac{\mathrm{OB} / \mathrm{ON}}{\mathrm{OG} / \mathrm{OH}}\right]^{1 / 2}=\frac{\mathrm{OB} / \mathrm{ON}}{\mathrm{OG} / \mathrm{OM}} \times\left[\frac{\mathrm{OG} / \mathrm{OM}}{\mathrm{OG} / \mathrm{OH}} \times \frac{\mathrm{OB} / \mathrm{OZ}}{\mathrm{OB} / \mathrm{ON}}\right]^{1 / 2} \\
& =\frac{\mathrm{OM} / \mathrm{OG}}{\mathrm{ON} / \mathrm{OB}} \times\left[\frac{\mathrm{OH}}{\mathrm{OM}} \times \frac{\mathrm{ON}}{\mathrm{OZ}}\right]^{1 / 2}=\mathrm{OEC} \times \mathrm{CTC} ;
\end{aligned}
$$




$$
\begin{aligned}
\mathrm{AM} & =\left[\frac{\mathrm{OC} / \mathrm{OZ}}{\mathrm{OE} / \mathrm{OM}} \times \frac{\mathrm{OA} / \mathrm{ON}}{\mathrm{OF} / \mathrm{OH}}\right]^{1 / 2}=\frac{\mathrm{OA} / \mathrm{ON}}{\mathrm{OE} / \mathrm{OM}} \times\left[\frac{\mathrm{OE} / \mathrm{OM}}{\mathrm{OF} / \mathrm{OH}} \times \frac{\mathrm{OC} / \mathrm{OZ}}{\mathrm{OA} / \mathrm{ON}}\right]^{1 / 2} \\
& =\frac{\mathrm{OM} / \mathrm{OE}}{\mathrm{ON} / \mathrm{OA}} \times\left[\frac{\mathrm{OE} / \mathrm{OM}}{\mathrm{OF} / \mathrm{OH}} \times \frac{\mathrm{OC} / \mathrm{OZ}}{\mathrm{OA} / \mathrm{ON}}\right]^{1 / 2}=\mathrm{AEC} \times \mathrm{ATC} .
\end{aligned}
$$

\subsubsection{Relationships among CM, IM and $A M$}

We know that a DMU (profit or non-profit organization) needs to be managed, for best use of production, and minimum cost and resources., hence it has to accomplish goals by using available resources efficiently. In the following, we will discuss the relationships among the $\mathrm{CM}$, IM and $\mathrm{AM}$ in the framework of organization management.

We refer readers to the Farrell decomposition (5): OE = TE $\times$ AE. Using (7) - (11), we have the relationships among $\mathrm{CM}$, IM and $\mathrm{AM}$, that is, $\mathrm{CM}=\mathrm{IM} \times \mathrm{AM}$ as follows:

$$
\begin{aligned}
\mathrm{CM} & =\left[\frac{w^{t} x^{t+1} / C^{t}\left(y^{t+1}, w^{t}\right)}{w^{t} x^{t} / C^{t}\left(y^{t}, w^{t}\right)} \times \frac{w^{t+1} x^{t+} / C^{t+} y^{t+} w^{t+}}{w^{t+1} x^{t} / C^{t+1}\left(y^{t}, w^{t+}\right)}\right]^{1 / 2} \\
& =\left[\frac{D^{t}\left(y^{t+1}, x^{t+1}\right)}{D^{t}\left(y^{t}, x^{t}\right)} \times \frac{D^{t+}\left(y^{t+1}, x^{t+}\right)^{1}}{D^{t+1}\left(y^{t}, x^{t}\right)}\right]^{1 / 2} \times \\
& {\left[\frac{w^{t} x^{t+1} / C^{t}\left(y^{t+1}, w^{t}\right) D^{t}\left(y^{t+1}, x^{t+}\right)}{w^{t} x^{t} / C^{t}\left(y^{t}, w^{t}\right) D^{t}\left(y^{t}, x^{t}\right)} \times \frac{w^{t+1} x^{t+1} / C^{t+1}\left(y^{t+1}, w^{t+1}\right) D^{t+1}\left(y^{t+1}, x^{t+1}\right)}{w^{t+1} x^{t} / C^{t+1}\left(y^{t}, w^{t+1}\right) D^{t+1}\left(y^{t}, x^{t}\right)}\right]^{1 / 2} } \\
& =\mathrm{IM} \times \mathrm{AM} .
\end{aligned}
$$

Similarly, we have:

$$
\begin{aligned}
\mathrm{OEC} & =\frac{w^{t+1} x^{t+1} / C^{t+}\left(y^{t+1}, w^{t+1}\right)}{\left.w^{t} x^{t} / C^{t} y^{t}, w^{t}\right)} \\
& =\frac{D^{t+1}\left(y^{t+1}, x^{t+1}\right)}{D^{t}\left(y^{t}, x^{t}\right)} \times \frac{w^{t+1} x^{t+1} C^{t+}\left(y^{t+1}, w^{t+1}\right) D^{t+}\left(y^{t+1}, x\right.}{w^{t} x^{t} C^{t}\left(y^{t}, w^{t}\right) D^{t}\left(y^{t}, x^{t}\right)} \\
& =\mathrm{TEC} \times \mathrm{AEC} .
\end{aligned}
$$

Therefore we obtain: 


$$
\begin{aligned}
\mathrm{CTC} & =\left[\frac{w^{t} x^{t+1} / C^{t}\left(y^{t+1}, w^{t}\right)}{w^{t+1} x^{t+1} / C^{t+1}\left(y^{t+1}, w^{t+1}\right)} \times \frac{w^{t} x^{t} / C^{t}\left(y^{t}, w^{t}\right)}{w^{t+1} x^{t} / C^{t+1}\left(y^{t}, w^{t+1}\right)}\right]^{1 / 2} \\
& =\left[\frac{D^{t}\left(y^{t}, x^{t}\right)}{D^{t+1}\left(y^{t}, x^{t}\right)} \times \frac{D^{t}\left(y^{t+1}, x^{t+1}\right)}{D^{t+1}\left(y^{t+1}, x^{t+1}\right)}\right]^{1 / 2} \times \\
& {\left[\frac{w^{t} x^{t+1} / C^{t}\left(y^{t+1}, w^{t}\right) D^{t}\left(y^{t+1}, x^{t+1}\right)}{w^{t} x^{t} / C^{t}\left(y^{t}, w^{t}\right) D^{t}\left(y^{t}, x^{t}\right)} \times \frac{w^{t+1} x^{t+1} / C^{t+1}\left(y^{t+1}, w^{t+1}\right) D^{t+1}\left(y^{t+1}, x^{t+1}\right)}{w^{t+1} x^{t} / C^{t+1}\left(y^{t}, w^{t+1}\right) D^{t+1}\left(y^{t}, x^{t}\right)}\right]^{1 / 2} } \\
= & \operatorname{TC} \times \text { ATC. }
\end{aligned}
$$

Using (7), (17) and the considering that TEC=SEC $\times$ PTEC as given by Färe et al. (1996) (see also Ray and Desli, 1997), the CM index can be further decomposed as follows:

$$
\begin{aligned}
\mathrm{CM}= & \mathrm{OEC} \times \mathrm{CTC} \\
& =[\mathrm{TEC} \times \mathrm{AEC}] \times[\mathrm{TC} \times \mathrm{ATC}] \\
& =[\mathrm{TEC} \times \mathrm{TC}] \times[\mathrm{AEC} \times \mathrm{ATC}] \\
& =\{[\mathrm{SEC} \times \mathrm{PTEC}] \times \mathrm{TC}\} \times[\mathrm{AEC} \times \mathrm{ATC}] \\
& =\mathrm{IM} \times \mathrm{AM} .
\end{aligned}
$$

where:

OEC $=$ overall efficiency change

$\mathrm{CTC}=$ cost technical change

TEC $=$ technical efficiency change

$\mathrm{AEC}=$ allocative efficiency change

$\mathrm{TC}=$ technical change

ATC $=$ allocation-technical change

SEC $=$ scale efficiency change

PTEC $=$ pure technical efficiency change

$\mathrm{TC}=$ technical change

$\mathrm{AEC}=$ allocative efficiency change

ATC $=$ allocation-technical change

Here, we need to point out that the computation of the indices and their components (the distance function $D$ and cost function $C$, etc.) are based on the linear programming models provided in Section 5 of Maniadakis and Thanassoulis (2004). Software such as GAMS can be used for computing the indices. As indicated in Section 1, the decompositions in (18) provides a clearer picture of the root sources of the productivity change of the $\mathrm{CM}$, IM and $\mathrm{AM}$, respectively.

\section{An application in the China securities industry}

In this section we illustrate the proposed approach of the CM, IM and AM on the data 
set of 40 China's securities companies in the framework of corporate management during the period 2005-2011.

\subsection{The China securities industry}

As an important component of the financial industry in mainland China, the securities industry with banking industry and insurance industry are known as the "Troika". It plays a role of booster and lubricant for China's economic development and relates to the healthy development of the China's economy and securities market. The development of China's macroeconomic, investors' concern on the securities market and continual improvement of regulatory approach provide good opportunities for the development of the China securities industry. As important intermediaries in the securities market, the China securities companies were growing up in the exploration and reform, and had played the key role to the breeding and development of the whole industry.

From 2005 to 2011, under the tough external environment and internal industry comprehensive governance (China Securities Regulatory Commission, 2005), the China securities industry was developed steadily. There were 115 and 109 securities companies in the industry in 2005 and 2011, respectively. In 2011, the average assets of the securities companies totaled RMB 831.3 billion yuan (1 US\$ = approx. 6.3009 yuan in 2011), RMB 513.1 billion yuan more than in 2005. In the stock market, there were 2,342 listed companies in the Shanghai and Shenzhen stock exchanges, 961 more than in 2005. See The People's Bank of China (2006-2012).

However, large increase in the Chines Securities companies is also produced a lot of problems in corporate management in the China's securities companies. Some securities companies are still inadequate in cost management, production management, resource allocation management, development scale, making-profit models, etc. Cost increase, production (service) based on excessive inputs, (human, assets, etc.) resource allocation not properly done and many other issues have affected the strength of competitiveness and capability of sustainable development of the China securities 
companies.

In the following, an application of the allocation Malmquist index in the mainland China securities industry is discussed; the relevant efficiencies and productivities are investigated as well.

\subsection{Sample and index selections}

Data used in this study is gathered from annual financial statements as published by the China securities companies from 2005 to 2011. The statements of 2006-2011 can also be found intensively in the publication of the Securities Association of China (2013).

In China, there are two kinds of the securities companies, brokerage or integrated securities companies. The former is just running securities brokerage business; the latter is running not just brokerage, but also other businesses concerning securities. Due to DEA requirement and to analyze homogenize DMUs, this paper takes only the 40 integrated securities companies as the research objects.

In China, according to Article 125 of the Securities Law (The National People's Congress, 2005), a securities firm may undertake some or all the following business operations: (a) Securities brokerage; (b) Self-operation of securities; (c) Underwriting and recommendation of securities; (d) Securities Investment consulting; (e) Financial advising relating to activities of securities trading or securities investment; (f) Securities asset management; and (g) Any other business operation concerning securities. Here, (a) ${ }^{-}$(c) consist of three traditional businesses. In addition, with gradually opening the China capital market, the securities companies have entered to (d)-(f) to expand their business space and promote the capability of business innovation. This paper classifies these three businesses as innovation business. Hence, we used the following output variables.

\section{Outputs:}

Output $1\left(y_{1}\right)$ : brokerage income (unit: 1,000,000 yuan);

Output $2\left(y_{2}\right)$ : self-operation income (unit: 1,000,000 yuan); 
Output $3\left(y_{3}\right)$ : underwriting income (unit: 1,000,000 yuan);

Output $4\left(y_{4}\right)$ : innovation income (unit: 1,000,000 yuan) and

Output 5 ( $\left.y_{5}\right)$ : other income (unit: 1,000,000 yuan).

In a firm, the number of employee and the average total assets represent the human capital and total economic resource of the firm, respectively. As a securities company is a knowledge-intensive firm and referring the previous scholars' work, we used the two items as two kinds of input variables of rare resources.

\section{Inputs:}

Input $1\left(x_{1}\right)$ : the total number of employee (unit: person) and Input $2\left(x_{2}\right)$ : the average total assets (unit: 1,000,000 yuan);

For this study we also used the following prices.

\section{Input prices:}

Input price $1\left(w_{1}\right)$ : the average employee wages (total employee wages/total number of employee) (unit: 1,000 yuan/per person) and

Input price $2\left(w_{2}\right)$ : the ratio of the revenue expenditure and average total assets (revenue expenditure/average total assets).

Table 1 below illustrates a summary statistics of the panel data of the 7 years average values of input, output variables as well as price indexes for 40 sample companies from 2005 to 2011 (see Appendix 1 for details).

Table 1: Descriptive statistics of the average values from 2005 to 2011

\begin{tabular}{lccccccccc}
\hline & $y_{1}$ & $y_{2}$ & $y_{3}$ & $y_{4}$ & $y_{5}$ & $x_{1}$ & $x_{2}$ & $w_{1}$ & $w_{2}$ \\
\hline Mean & 1735.564 & 5765.492 & 216.888 & 220.483 & 48.791 & 2,258 & 22628.040 & 235.825 & 0.035 \\
\hline SD & 1760.377 & 10261.388 & 324.250 & 402.187 & 57.824 & 1988.576 & 25054.957 & 93.701 & 0.008 \\
\hline Min & 201.037 & 600.357 & 2.669 & 18.475 & 4.397 & 522 & 3646.984 & 126.386 & 0.023 \\
\hline Max & 7438.985 & 41615.236 & 1787.119 & 2458.524 & 279.376 & 9.246 & 117986.660 & 556.724 & 0.061 \\
\hline
\end{tabular}

Data source: Annual reports of the 40 China's securities companies from 2005 to 2011 .

\subsection{Results and discussion}

\subsubsection{Efficiencies of the China securities companies}


To Show the usefulness of the proposed indices in this paper we provide and compare the efficiencies of the China securities companies during 2005 to 2011 (see Appendix 2). It can be seen that, the China securities industry in 2011 was cost inefficient (0.625) due to the industry was both of productively and allocatively inefficient, but the value of TE $(=0.810)$ was higher than the AE's $(=0.767)$, i.e., the TE was less influential than the AE to the OE of the industry in 2011. In 2011, 6 DMUs, including 3, 26, 27, 32, 38 and 39, were fully allocatively and fully technical efficient ( $\mathrm{AE}=1 \& \mathrm{TE}=1)$. DMU 6, 21 and 23 were fully allocative efficient but not technically efficient.

Furthermore, at overall industry level, Table 2 summarizes the Means and Standard division of the OE, TE and AE of the 40 sample companies, in each year of 2005-2011, showing that overall the China securities industry was cost inefficient every year. The reason was that the industry was both of productively and allocatively inefficient. The TE was less influential than the AE to the OE of the China securities industry except 2005.

Table 2. The Means of the OE, TE and AE of the 40 companies from 2005 to 2011

\begin{tabular}{cccccccc}
\hline & 2005 & 2006 & 2007 & 2008 & 2009 & 2010 & 2011 \\
\hline OE Mean & 0.705 & 0.321 & 0.590 & 0.645 & 0.571 & 0.615 & 0.625 \\
\hline TE Mean & 0.838 & 0.667 & 0.879 & 0.834 & 0.877 & 0.860 & 0.810 \\
\hline AE Mean & 0.839 & 0.465 & 0.665 & 0.772 & 0.641 & 0.717 & 0.767 \\
\hline OE SD & 0.207 & 0.227 & 0.221 & 0.190 & 0.246 & 0.227 & 0.228 \\
\hline TE SD & 0.169 & 0.185 & 0.104 & 0.141 & 0.137 & 0.151 & 0.163 \\
\hline AE SD & 0.159 & 0.231 & 0.208 & 0.172 & 0.221 & 0.217 & 0.200 \\
\hline
\end{tabular}

\subsubsection{Malmquist indexes of the China securities companies}

In the following, firstly, we use decomposition given in (11) to explain the reasons behind the productivity changes of the CM, IM and AM in the China securities industry in 2010-2011 [Note that similar results have been obtained for other periods, (2005-6, 2006-7, 2008-9 \& 2009-10), in the next section we present overall results for the whole study period 2005-2011].

Table 3: The CM, IM and AM of the 40 companies between 2010 and 2011 


\begin{tabular}{|c|c|c|c|c|c|c|c|c|c|}
\hline \multirow[b]{2}{*}{$\mathrm{DMU}$} & \multicolumn{3}{|c|}{ CM Index } & \multicolumn{3}{|c|}{ IM Index } & \multicolumn{3}{|c|}{ AM Index } \\
\hline & $\mathrm{CM}^{\mathrm{a}}$ & $\mathrm{OEC}$ & CTC & $\mathrm{IM}^{\mathrm{b}}$ & TEC & $\mathrm{TC}$ & $\mathrm{AM}^{\mathrm{c}}$ & $\mathrm{AEC}$ & ATC \\
\hline 1 & 0.853 & 0.671 & 1.272 & 1.141 & 1.042 & 1.095 & 0.747 & 0.643 & 1.161 \\
\hline 2 & 1.517 & 1.059 & 1.432 & 1.291 & 1.191 & 1.084 & 1.175 & 0.889 & 1.321 \\
\hline 3 & 0.383 & 0.360 & 1.061 & 0.405 & 0.529 & 0.766 & 0.945 & 0.682 & 1.386 \\
\hline 4 & 0.717 & 0.569 & 1.260 & 0.810 & 0.850 & 0.952 & 0.885 & 0.669 & 1.323 \\
\hline 5 & 1.305 & 0.871 & 1.497 & 1.183 & 1.164 & 1.016 & 1.103 & 0.748 & 1.474 \\
\hline 6 & 1.513 & 1.256 & 1.204 & 1.513 & 1.257 & 1.204 & 1.000 & 1.000 & 1.000 \\
\hline 7 & 1.496 & 1.100 & 1.360 & 1.290 & 1.209 & 1.067 & 1.159 & 0.910 & 1.274 \\
\hline 8 & 2.002 & 1.305 & 1.534 & 1.146 & 1.115 & 1.028 & 1.747 & 1.171 & 1.492 \\
\hline 9 & 1.991 & 1.256 & 1.585 & 1.499 & 1.105 & 1.357 & 1.328 & 1.137 & 1.168 \\
\hline 10 & 1.381 & 0.996 & 1.387 & 1.096 & 1.004 & 1.093 & 1.260 & 0.992 & 1.269 \\
\hline 11 & 2.232 & 1.490 & 1.499 & 1.352 & 1.185 & 1.141 & 1.651 & 1.257 & 1.313 \\
\hline 12 & 1.735 & 1.309 & 1.326 & 1.488 & 1.258 & 1.183 & 1.166 & 1.041 & 1.121 \\
\hline 13 & 1.017 & 0.866 & 1.174 & 0.900 & 0.824 & 1.093 & 1.130 & 1.052 & 1.074 \\
\hline 14 & 1.070 & 0.700 & 1.528 & 1.003 & 1.000 & 1.003 & 1.067 & 0.700 & 1.524 \\
\hline 15 & 1.393 & 0.994 & 1.401 & 1.289 & 1.155 & 1.116 & 1.081 & 0.861 & 1.256 \\
\hline 16 & 1.083 & 0.673 & 1.610 & 0.955 & 0.750 & 1.272 & 1.134 & 0.897 & 1.265 \\
\hline 17 & 1.332 & 0.928 & 1.435 & 1.162 & 0.944 & 1.231 & 1.146 & 0.983 & 1.166 \\
\hline 18 & 1.813 & 1.249 & 1.451 & 1.695 & 1.246 & 1.361 & 1.069 & 1.003 & 1.066 \\
\hline 19 & 1.194 & 0.740 & 1.613 & 1.002 & 0.949 & 1.056 & 1.191 & 0.780 & 1.528 \\
\hline 20 & 1.559 & 1.139 & 1.369 & 1.291 & 1.054 & 1.225 & 1.207 & 1.080 & 1.118 \\
\hline 21 & 1.018 & 0.760 & 1.340 & 1.040 & 0.787 & 1.321 & 0.979 & 0.965 & 1.015 \\
\hline 22 & 1.663 & 1.263 & 1.317 & 1.139 & 1.087 & 1.048 & 1.460 & 1.162 & 1.257 \\
\hline 23 & 1.455 & 0.898 & 1.621 & 1.452 & 1.095 & 1.326 & 1.002 & 0.820 & 1.223 \\
\hline 24 & 1.169 & 0.864 & 1.354 & 1.002 & 0.928 & 1.080 & 1.167 & 0.931 & 1.254 \\
\hline 25 & 1.032 & 0.632 & 1.633 & 0.950 & 0.979 & 0.971 & 1.086 & 0.645 & 1.682 \\
\hline 26 & 1.492 & 0.996 & 1.499 & 1.330 & 1.000 & 1.330 & 1.122 & 0.996 & 1.127 \\
\hline 27 & 1.054 & 0.613 & 1.719 & 1.122 & 1.000 & 1.122 & 0.940 & 0.613 & 1.533 \\
\hline 28 & 1.448 & 0.905 & 1.600 & 1.309 & 1.218 & 1.074 & 1.106 & 0.743 & 1.489 \\
\hline 29 & 1.498 & 1.006 & 1.489 & 1.381 & 1.177 & 1.173 & 1.084 & 0.854 & 1.269 \\
\hline 30 & 2.329 & 2.501 & 0.931 & 2.212 & 2.448 & 0.904 & 1.053 & 1.022 & 1.031 \\
\hline 31 & 1.989 & 1.211 & 1.642 & 1.665 & 1.170 & 1.423 & 1.194 & 1.035 & 1.154 \\
\hline 32 & 0.999 & 1.000 & 0.999 & 0.940 & 1.000 & 0.940 & 1.063 & 1.000 & 1.063 \\
\hline 33 & 2.048 & 1.803 & 1.136 & 1.599 & 1.428 & 1.120 & 1.281 & 1.263 & 1.014 \\
\hline 34 & 1.452 & 0.989 & 1.467 & 1.196 & 1.113 & 1.075 & 1.214 & 0.889 & 1.366 \\
\hline 35 & 1.426 & 1.000 & 1.425 & 1.341 & 1.164 & 1.153 & 1.063 & 0.860 & 1.236 \\
\hline 36 & 1.527 & 1.033 & 1.478 & 1.321 & 0.968 & 1.365 & 1.156 & 1.068 & 1.083 \\
\hline 37 & 2.263 & 1.768 & 1.280 & 1.247 & 1.062 & 1.174 & 1.815 & 1.664 & 1.090 \\
\hline 38 & 0.817 & 1.000 & 0.817 & 0.824 & 1.000 & 0.824 & 0.991 & 1.000 & 0.991 \\
\hline 39 & 1.700 & 1.000 & 1.700 & 1.700 & 1.000 & 1.700 & 1.000 & 1.000 & 1.000 \\
\hline 40 & 1.496 & 0.989 & 1.514 & 1.360 & 1.313 & 1.036 & 1.100 & 0.753 & 1.461 \\
\hline G. Mean & 1.362 & 0.986 & 1.382 & 1.200 & 1.067 & 1.125 & 1.135 & 0.924 & 1.229 \\
\hline SD & 0.432 & 0.373 & 0.205 & 0.305 & 0.273 & 0.172 & 0.207 & 0.202 & 0.177 \\
\hline
\end{tabular}

${ }^{\mathrm{a}} \mathrm{CM}=\mathrm{OEC} \times \mathrm{CTC}=\mathrm{IM} \times \mathrm{AM} ;{ }^{\mathrm{b}} \mathrm{IM}=\mathrm{TEC} \times \mathrm{TC} ;{ }^{\mathrm{c}} \mathrm{AM}=\mathrm{AEC} \times \mathrm{ATC}$.

According to Table 3, at overall industry level, it can be seen that between 2010 and 2011, the CM, IM and AM of the China securities industry, represented by the geometric means of the CM, IM and AM of the 40 sample companies, have relationships: 


$$
\begin{aligned}
1.362 & =0.986 \times 1.382=(1.067 \times 0.924) \times(1.125 \times 1.229) \\
& =(1.067 \times 1.125) \times(0.924 \times 1.229)=1.200 \times 1.135 .
\end{aligned}
$$

From the cost management point of view, the reason of the cost Malmquist index of the securities industry regress $(\mathrm{CM}=1.362)$ between 2010 and 2011 can be considered as the overall efficiency increase $(\mathrm{OEC}=0.986)$ and the cost technology regress (CTC $=1.382$ ) between 2010 and 2011. However, the overall efficiency increase was less influential than the cost technology regress to the CM because $0.014=\mid 1-$ OEC $|<| 1-$ CTC $\mid=0.382$. We can also see that the cost technology regress were affected by both of the production technology and allocation technology regress ( $\mathrm{TC}=1.125$ and $\mathrm{ATC}=1.229$ ), and the influential effect brought by the production technology change was less than the allocation technology change.

From the productivity measurement point of view, the CM regress was due to both of the input-oriented Malmquist index and allocation Malmquist index regress (IM=1.200 and $A M=1.135$ ) of the securities industry between 2010 and 2011. The IM was more influential than the AM to the CM index.

From production management point of view, the reason of the IM of the industry regress between 2010 and 2011 was due to both of the technical efficiency decrease $(\mathrm{TEC}=1.067)$ and production technology regress $(\mathrm{TC}=1.125)$. The former was less influential than the latter to the IM index of the industry.

From resource allocation management point of view, the AM of the securities industry regress between 2010 and 2011 was mainly caused by the allocation technology regress $(\mathrm{ATC}=1.229)$ although the allocative efficiency increase $(\mathrm{AEC}=0.924)$ brought a positive effect to the AM index, see Table 4. Six DMUs, including 1, 3, 4, 21, 27 and 38, had the AM progress $(\mathrm{AM}<1)$. DMU 6 and 39 were the constant allocative productivity $(\mathrm{AM}=1)$ because these 2 DMUs were the constant allocation efficiency and constant technology $(\mathrm{AEC}=\mathrm{ATC}=1)$. The other $32 \mathrm{DMUs}$ were the AM regress $(\mathrm{AM}>1)$. 
Similarly, based on Formula (11) and Table 4, we can also discuss the CM, IM and AM indexes at individual DMU level between 2010 and 2011. DMU 12, for example, had $1.735=1.488 \times 1.166$, where $\mathrm{CM}=1.735$, $\mathrm{IM}=1.488$ and $\mathrm{AM}=1.166$. Because IM>AM, the CM of DMU 12 regress was due to both of the IM and AM regress, but the IM was more influential than the AM to the CM index between 2010 and 2011.

DMU 38, as another example, had $0.817=0.824 \times 0.991$, where $\mathrm{CM}=0.817, \mathrm{IM}=0.824$ and $\mathrm{AM}=0.991$. Since $\mathrm{IM}<\mathrm{AM}$, the $\mathrm{CM}$ of DMU 38 progress was due to both of its IM and AM progress, but the IM was more influential than the AM to the CM index between 2010 and 2011. From Table 2 and Appendix 2, DMU 38 was $\mathrm{OE}=\mathrm{TE}=\mathrm{AE}=1$ in 2010 and 2011, respectively. In fact, this DMU was the largest scale securities company among the 40 sample companies: the inputs $\left(x_{1}, x_{2}\right)$ of the number of employee and the average total assets were $(15,476,179992.56)$ and $(13,260$, 150729.03) in 2010 and 2011, respectively.

Secondly, at overall industry level, Table 4 summarizes the values of the CM, IM and AM of the China securities industry from 2005 to 2011 by the geometric means of the CM, IM and AM of the 40 sample companies.

Table 4: The G. Means of the CM, IM and AM of the 40 companies from 2005 to 2011

\begin{tabular}{cccccccccc}
\hline & \multicolumn{3}{c}{ CM Index } & \multicolumn{3}{c}{ IM Index } & \multicolumn{3}{c}{ AM Index } \\
\hline Time & CM & OEC & CTC & IM & TEC & TC & AM & AEC & ATC \\
\hline $2005-2006$ & 0.703 & 2.511 & 0.280 & 0.713 & 1.274 & 0.560 & 0.986 & 1.970 & 0.501 \\
\hline $2006-2007$ & 1.387 & 0.486 & 2.853 & 1.989 & 0.736 & 2.701 & 0.697 & 0.660 & 1.056 \\
\hline $2007-2008$ & 0.791 & 0.892 & 0.886 & 0.994 & 1.062 & 0.936 & 0.796 & 0.840 & 0.947 \\
\hline $2008-2009$ & 3.127 & 1.188 & 2.632 & 2.109 & 0.951 & 2.217 & 1.482 & 1.249 & 1.187 \\
\hline $2009-2010$ & 1.393 & 0.903 & 1.542 & 1.350 & 1.023 & 1.321 & 1.032 & 0.884 & 1.167 \\
\hline $2010-2011$ & 1.362 & 0.986 & 1.382 & 1.200 & 1.067 & 1.125 & 1.135 & 0.924 & 1.229 \\
\hline $2005-2011$ & 1.288 & 1.024 & 1.258 & 1.300 & 1.006 & 1.292 & 0.991 & 1.018 & 0.974 \\
\hline
\end{tabular}

From Table 5, we can see that between 2005 and 2006, the IM progress (IM=0.713) of the China securities industry was due to its technical efficiency decrease (TEC=1.274) but production technology progress $(\mathrm{TC}=0.560)$. Zhu and Liu (2008) discussed the IM and its components of the China securities industry between 2005 and 2006. They 
concluded that the technical efficiency decrease was due to both of the scale efficiency and pure technical efficiency decrease between 2005 and 2006.

Finally, Table 5 is given the geometric means of the CM, IM and AM of the 40 securities companies between 2005 and 2011.

Table 5: The G. Means of the CM, IM and AM of the 40 companies between 2005 and 2011

\begin{tabular}{|c|c|c|c|c|c|c|c|c|c|}
\hline \multirow[b]{2}{*}{ DMU } & \multicolumn{3}{|c|}{ CM Index } & \multicolumn{3}{|c|}{ IM Index } & \multicolumn{3}{|c|}{ AM Index } \\
\hline & $\mathrm{CM}$ & $\mathrm{OEC}$ & CTC & IM & TEC & $\mathrm{TC}$ & $\mathrm{AM}$ & AEC & ATC \\
\hline 1 & 1.208 & 0.969 & 1.246 & 1.327 & 0.992 & 1.338 & 0.910 & 0.978 & 0.931 \\
\hline 2 & 1.495 & 0.990 & 1.511 & 1.592 & 1.030 & 1.545 & 0.939 & 0.961 & 0.978 \\
\hline 3 & 1.297 & 1.000 & 1.297 & 1.328 & 1.000 & 1.328 & 0.977 & 1.000 & 0.977 \\
\hline 4 & 1.598 & 0.950 & 1.682 & 1.604 & 1.000 & 1.604 & 0.997 & 0.950 & 1.049 \\
\hline 5 & 1.224 & 1.062 & 1.153 & 1.193 & 1.014 & 1.176 & 1.026 & 1.047 & 0.980 \\
\hline 6 & 1.222 & 0.954 & 1.282 & 1.337 & 0.966 & 1.385 & 0.914 & 0.988 & 0.925 \\
\hline 7 & 1.459 & 1.061 & 1.375 & 1.391 & 1.018 & 1.366 & 1.049 & 1.042 & 1.007 \\
\hline 8 & 1.315 & 1.201 & 1.095 & 1.058 & 1.013 & 1.045 & 1.242 & 1.185 & 1.048 \\
\hline 9 & 1.114 & 1.009 & 1.105 & 1.108 & 0.992 & 1.117 & 1.006 & 1.017 & 0.989 \\
\hline 10 & 1.230 & 1.052 & 1.170 & 1.259 & 1.006 & 1.252 & 0.977 & 1.045 & 0.934 \\
\hline 11 & 1.474 & 1.083 & 1.361 & 1.525 & 1.066 & 1.431 & 0.966 & 1.016 & 0.951 \\
\hline 12 & 1.419 & 1.132 & 1.253 & 1.405 & 1.090 & 1.289 & 1.009 & 1.038 & 0.972 \\
\hline 13 & 1.341 & 1.077 & 1.245 & 1.385 & 1.054 & 1.314 & 0.968 & 1.022 & 0.947 \\
\hline 14 & 1.445 & 0.990 & 1.460 & 1.462 & 0.982 & 1.489 & 0.989 & 1.008 & 0.980 \\
\hline 15 & 1.338 & 1.127 & 1.187 & 1.216 & 1.024 & 1.187 & 1.100 & 1.100 & 1.000 \\
\hline 16 & 1.431 & 1.009 & 1.418 & 1.326 & 1.000 & 1.326 & 1.080 & 1.009 & 1.070 \\
\hline 17 & 1.030 & 0.911 & 1.131 & 1.174 & 0.996 & 1.179 & 0.877 & 0.914 & 0.959 \\
\hline 18 & 1.329 & 1.009 & 1.318 & 1.408 & 1.009 & 1.397 & 0.944 & 1.000 & 0.943 \\
\hline 19 & 1.400 & 1.104 & 1.268 & 1.170 & 1.012 & 1.157 & 1.196 & 1.091 & 1.096 \\
\hline 20 & 1.256 & 0.958 & 1.311 & 1.330 & 0.963 & 1.380 & 0.944 & 0.994 & 0.950 \\
\hline 21 & 1.081 & 0.891 & 1.213 & 1.209 & 0.908 & 1.332 & 0.895 & 0.982 & 0.911 \\
\hline 22 & 1.121 & 1.018 & 1.101 & 1.154 & 0.953 & 1.211 & 0.971 & 1.068 & 0.909 \\
\hline 23 & 1.248 & 1.041 & 1.199 & 1.322 & 1.046 & 1.264 & 0.944 & 0.995 & 0.949 \\
\hline 24 & 1.503 & 1.140 & 1.319 & 1.357 & 1.007 & 1.347 & 1.108 & 1.132 & 0.979 \\
\hline 25 & 1.228 & 0.972 & 1.264 & 1.254 & 0.958 & 1.308 & 0.980 & 1.014 & 0.966 \\
\hline 26 & 1.116 & 0.944 & 1.182 & 1.189 & 0.973 & 1.222 & 0.938 & 0.971 & 0.967 \\
\hline 27 & 1.163 & 0.961 & 1.210 & 1.189 & 0.974 & 1.220 & 0.978 & 0.986 & 0.992 \\
\hline 28 & 1.572 & 0.948 & 1.658 & 1.657 & 1.004 & 1.651 & 0.949 & 0.944 & 1.005 \\
\hline 29 & 1.242 & 1.011 & 1.228 & 1.241 & 0.971 & 1.279 & 1.001 & 1.042 & 0.960 \\
\hline 30 & 1.376 & 1.025 & 1.342 & 1.475 & 1.056 & 1.397 & 0.933 & 0.971 & 0.961 \\
\hline 31 & 1.159 & 0.969 & 1.197 & 1.187 & 0.973 & 1.221 & 0.976 & 0.996 & 0.980 \\
\hline
\end{tabular}




\begin{tabular}{cccccccccc}
\hline 32 & 1.207 & 1.000 & 1.207 & 1.288 & 1.000 & 1.288 & 0.937 & 1.000 & 0.937 \\
\hline 33 & 1.309 & 1.155 & 1.133 & 1.307 & 1.061 & 1.232 & 1.002 & 1.089 & 0.920 \\
\hline 34 & 1.376 & 1.029 & 1.337 & 1.323 & 0.954 & 1.387 & 1.040 & 1.079 & 0.964 \\
\hline 35 & 1.144 & 1.018 & 1.124 & 1.228 & 1.040 & 1.181 & 0.931 & 0.979 & 0.952 \\
\hline 36 & 1.177 & 1.106 & 1.064 & 1.152 & 1.082 & 1.065 & 1.021 & 1.022 & 0.999 \\
\hline 37 & 1.221 & 1.114 & 1.096 & 1.101 & 1.010 & 1.090 & 1.109 & 1.103 & 1.006 \\
\hline 38 & 1.162 & 1.000 & 1.162 & 1.172 & 1.000 & 1.172 & 0.991 & 1.000 & 0.991 \\
\hline 39 & 1.668 & 1.000 & 1.668 & 1.722 & 1.000 & 1.722 & 0.969 & 1.000 & 0.969 \\
\hline 40 & 1.177 & 1.057 & 1.113 & 1.204 & 1.059 & 1.138 & 0.977 & 0.999 & 0.978 \\
\hline G. Mean & 1.288 & 1.024 & 1.258 & 1.300 & 1.006 & 1.292 & 0.991 & 1.018 & 0.974 \\
\hline SD & 0.150 & 0.069 & 0.154 & 0.154 & 0.038 & 0.151 & 0.075 & 0.053 & 0.040 \\
\hline
\end{tabular}

At overall industry level, based on (11) and Table 5, it can be seen that the overall CM, IM and AM of the China securities industry between 2005 and 2011 had relationship:

$$
\begin{aligned}
1.288 & =1.024 \times 1.258=(1.006 \times 1.018) \times(1.292 \times 0.974) \\
& =(1.006 \times 1.292) \times(1.018 \times 0.974)=1.300 \times 0.991,
\end{aligned}
$$

where $\mathrm{CM}=1.288, \mathrm{OEC}=1.024, \mathrm{CTC}=1.258, \mathrm{TEC}=1.006, \mathrm{TC}=1.292, \mathrm{AEC}=1.018$, $\mathrm{ATC}=0.974, \mathrm{IM}=1.300$ and $\mathrm{AM}=0.991$.

We also observe that the CM of the China securities industry regresses between 2005 and 2011. Since OEC $<$ CTC, the CTC regress was the main factor to cause the CM regress. Considering $\mathrm{CTC}=\mathrm{TC} \times \mathrm{ATC}$, from (12.2), the $\mathrm{TC}$ was more influential than the ATC to the CTC although ATC=0.974.

The IM regress of the China securities industry between 2005 and 2011 was caused mainly by the TC rather than the TEC. However, we have the AM of the China securities industry progress between 2005 and 2011 (i.e. the ATC progress). The ATC was more influential than the AEC to the AM because $0.018=\mid 1-$ AEC $|<| 1-$ ATC $\mid=0.026$. We also have that the AM was less influential than the IM to the CM although $\mathrm{AM}=0.991$.

At DMU level, from Table 5, we can see that all CM and IM of the 40 sample DMUs regress individually between 2005 and 2011. However, we also have the AM of the 26 
DMUs progress, the AEC of the 15 DMUs increase and the ATC of the 32 DMUs progress between 2005 and 2011.

As another example, DMU 12 had 1.419=1.405×1.009, where CM=1.419, IM=1.405 and $A M=1.009$ between 2005 and 2011. Because $I M>A M$, the CM of DMU 12 regress was due to both of the IM and AM regress, but the IM regress was the main reason to cause the CM regress. Take DMU 38, $1.162=1.172 \times 0.991$, where $\mathrm{CM}=1.162$, $\mathrm{IM}=1.172$ and $\mathrm{AM}=0.991$. Because $0.172=|1-\mathrm{IM}|>|1-\mathrm{AM}|=0.009$, the main reason of the CM of DMU 38 regress was the IM regress, i.e., IM was more influential than the AM to the CM index between 2005 and 2011.

In order to promote the development of China securities industry to be sustainable, the cost-productivity change needs to be progressed. Based on this results of this analysis, we suggest that the relevant decision-makers should make right decisions in order to raise the overall efficiency up and promote the cost technology progress, esp., pay more attention to value of allocation Malmquist index which is closely affected by both of the production-technical change and allocation-technical change.

At the same time, the decision-makers must monitor the firm to make sure that the allocation-productivity change be progressed. For this, they have to choose decisions that increase the allocation efficiency. Allocative efficiency will be achieved when scarce resources (labor, capital, etc.) with a set of given resource prices are reasonably allocated so as to maximize the required outcomes of the securities companies.

\section{Conclusion}

In this paper, following the study of Maniadakis and Thanassoulis (2004), a concept of an allocation Malmquist index is proposed. Three kinds of Malmquist indexes of production, cost and allocation with their relationships in the framework of organization management are discussed. It is shown that the cost Malmquist index can be decomposed into the input-oriented (production) Malmquist index and allocation Malmquist index. 
An application in the China securities industry, represented by 40 companies, is provided. In terms of efficiency, we found that the China securities industry was cost inefficiently every year from 2005 to 2011 . The reason was that the industry was both of productively and allocatively inefficient. Except 2005, the technical efficiency was less influential than the allocative efficiency to the overall efficiency of the China securities industry from 2006 to 2011.

In terms of productivity change, the decompositions of the three types of Malmquist indexes illustrate the reasons of the productivity change of the China securities industry from 2005 to 2011. We found that the cost Malmquist index of the China securities industry regresses between 2005 and 2011. Since the value of the overall efficiency decrease was less than the value of the cost technology regress, the cost-technical change was the main factor to cause the cost Malmquist index regress.

We also showed that the allocation Malmquist index of the China securities industry progress between 2005 and 2011 was due to the allocation technology progress. The allocation technology progress was more influential than the allocation efficiency decrease to the allocation Malmquist index.

Further work could be investigation of the economic interpretation of the allocation Malmquist index, and finding the economic root sources of the productivity change of the cost, production and allocation Malmquist indexes. The sample size discussed in this study was 40 , hence, future study direction could be further investigating the performance of China securities companies by using more acquire data and large sample size, this is also a suggestion from authors that the China securities industry regulators should demand all kinds of the securities companies to release more information to the public for analyzing the securities industry and companies.

\section{References}

1. D.W. Caves, L.R. Christensen and W.E. Diewert, The economic theory of index numbers and the measurement of input, output and productivity, Econometrica, 50 (1982), pp.1393-1414.

2. A. Charnes, W.W. Cooper and E. Rhodes, Measuring the efficiency of decision making units, European Journal of Operational Research, 2 (1978), pp.429-444. 
3. China Securities Regulatory Commission, The work scheme of comprehensive governance of securities companies, 2005-07-29.

4. W.W. Cooper, L.M. Seiford and K. Tone, Data envelopment analysis: a comprehensive text with models, applications, references, and DEA-Solver software, Kluwer Academic Publishers, Second Printing 2000, pp.224.

5. A. Emrouznejad, B. Parker and G. Tavares, Evaluation of research in efficiency and productivity: A survey and analysis of the first 30 years of scholarly literature in DEA, Journal of Socio-Economics Planning Science, 42 (2008), pp.151-157.

6. A. Emrouznejad, , K. De Witte, COOPER-framework: A unified process for non-parametric projects. European Journal of Operational Research, 207 (2010) 1573-1586.

7. R. Färe, S. Grosskopf, M. Norris and Z. Zhang, Productivity growth, technical progress, and efficiency change in industrialized countries, American Economic Review, 84 (1994), pp.66-83.

8. R. Färe, S. Grosskopf and P. Roos, On two definitions of productivity, Economics Letters, 53 (1996), pp.269-274.

9. M.J. Farrell, The measurement of productive efficiency, Journal of the Royal Statistical Society, Series A, General 120 (1957), pp.253-281.

10. H. Fukuyama and W.L. Weber, Profit inefficiency of Japanese securities firms, Journal of Applied Economics, 11(2008), pp. 281-303.

11. L.G. Goldberg, G.A. Hanweck, M. Keenan and A. Young, Economies of scale and scope in the securities industry, Journal of Banking and Finance, 15 (1991), pp.91-107.

12. S. Malmquist, Index numbers and indifference surfaces, Trabajos de Estatistica, 4 (1953), pp.209-242.

13. N. Maniadakis and E. Thanassoulis, A cost Malmquist index, European Journal of Operational Research, 154 (2004), pp.396-409.

14. S.C. Ray and E. Delsi, Productivity growth, technical progress, and efficiency change in industrialized countries: comment, The American Economic Review, 87 (1997), pp.1033-1039.

15. Securities Association of China, http://www.sac.net.cn/newcn/home/index.html, Retrieved 2014-08-28.

16. The National People's Congress, Securities law of the People's Republic of China (revised), 2005-10-27.

17. The People's Bank of China, China Financial Stability Report, 2006-2012.

18. W. D. Zhang, S. Zhang and X. Luo, Technological progress, inefficiency, and productivity growth in the US securities industry, 1980-2000, Journal of Business Research, 59 (2006), pp.589-594.

19. N. Zhu and Y. Liu, The DEA analysis of productive efficiency of securities companies in China, Journal of Financial Research, 11 (2008), pp.120-137. (in Chinese). 
Appendix 1: The average values of inputs, outputs and price indexes from 2005 to 2011

\begin{tabular}{|c|c|c|c|c|c|c|c|c|c|}
\hline DMU & $y_{1}$ & $y_{2}$ & $y_{3}$ & $y_{4}$ & $y_{5}$ & $x_{1}$ & $x_{2}$ & $w_{1}$ & $w_{2}$ \\
\hline 1 & 833.413 & 2530.219 & 43.929 & 417.154 & 35.789 & 1660 & 11541.702 & 209.577 & 0.051 \\
\hline 2 & 1494.203 & 10779.663 & 92.089 & 71.349 & 56.398 & 3682 & 20861.757 & 126.580 & 0.035 \\
\hline 3 & 201.037 & 1222.699 & 44.955 & 31.120 & 19.095 & 522 & 3927.569 & 146.058 & 0.035 \\
\hline 4 & 271.665 & 21163.929 & 187.947 & 36.173 & 5.204 & 864 & 5486.974 & 215.936 & 0.042 \\
\hline 5 & 1017.604 & 1025.349 & 44.306 & 47.948 & 42.180 & 2087 & 11249.782 & 126.386 & 0.040 \\
\hline 6 & 1472.471 & 5094.234 & 179.923 & 263.822 & 40.502 & 1546 & 25534.718 & 362.614 & 0.029 \\
\hline 7 & 920.415 & 2012.395 & 74.077 & 123.193 & 11.906 & 1221 & 10338.910 & 226.842 & 0.053 \\
\hline 8 & 823.150 & 600.357 & 43.402 & 24.078 & 20.979 & 1316 & 7914.422 & 176.663 & 0.027 \\
\hline 9 & 1014.326 & 1048.724 & 95.081 & 42.040 & 14.528 & 961 & 11254.658 & 298.551 & 0.036 \\
\hline 10 & 2766.431 & 2155.358 & 276.461 & 464.217 & 51.048 & 3361 & 36165.250 & 310.170 & 0.029 \\
\hline 11 & 701.340 & 1557.168 & 6.609 & 18.475 & 14.220 & 849 & 6950.201 & 192.208 & 0.027 \\
\hline 12 & 4747.952 & 8384.504 & 410.968 & 331.765 & 82.842 & 6191 & 62848.347 & 304.301 & 0.028 \\
\hline 13 & 444.495 & 1233.076 & 60.281 & 53.175 & 18.233 & 973 & 11175.943 & 215.217 & 0.026 \\
\hline 14 & 1020.395 & 5958.265 & 92.061 & 34.670 & 17.455 & 1318 & 8969.044 & 197.507 & 0.061 \\
\hline 15 & 588.179 & 893.950 & 140.756 & 68.304 & 46.480 & 1417 & 6625.369 & 178.968 & 0.033 \\
\hline 16 & 830.196 & 2206.164 & 45.508 & 44.736 & 11.139 & 684 & 9051.694 & 145.068 & 0.035 \\
\hline 17 & 444.414 & 749.674 & 13.460 & 22.217 & 4.397 & 560 & 3646.984 & 130.378 & 0.046 \\
\hline 18 & 5429.641 & 37166.147 & 509.964 & 328.664 & 165.657 & 5862 & 73858.335 & 318.916 & 0.030 \\
\hline 19 & 4414.831 & 1861.226 & 547.773 & 422.047 & 279.376 & 6833 & 43541.348 & 226.397 & 0.032 \\
\hline 20 & 937.326 & 2329.450 & 106.764 & 57.841 & 37.873 & 1582 & 15834.828 & 178.240 & 0.029 \\
\hline 21 & 4444.152 & 3982.711 & 456.708 & 748.430 & 85.351 & 5318 & 71545.517 & 273.298 & 0.029 \\
\hline 22 & 1306.091 & 1441.602 & 200.676 & 83.744 & 45.271 & 2254 & 16842.504 & 175.026 & 0.032 \\
\hline 23 & 5296.518 & 3246.132 & 514.339 & 167.074 & 147.746 & 3964 & 60019.720 & 350.579 & 0.037 \\
\hline 24 & 443.500 & 1737.509 & 28.561 & 52.151 & 10.369 & 879 & 5302.883 & 207.258 & 0.041 \\
\hline 25 & 635.541 & 1689.107 & 163.356 & 40.605 & 7.606 & 1206 & 5853.545 & 150.342 & 0.043 \\
\hline 26 & 843.285 & 1117.804 & 36.606 & 31.986 & 14.343 & 804 & 8587.489 & 180.570 & 0.034 \\
\hline 27 & 875.656 & 4292.479 & 904.045 & 154.279 & 37.008 & 2339 & 17141.672 & 261.738 & 0.029 \\
\hline 28 & 2529.941 & 3432.213 & 89.513 & 104.467 & 68.289 & 3501 & 24084.492 & 159.575 & 0.040 \\
\hline 29 & 742.377 & 1122.616 & 91.817 & 45.156 & 14.296 & 1102 & 9804.161 & 195.572 & 0.023 \\
\hline 30 & 818.675 & 3567.947 & 14.576 & 31.248 & 24.753 & 1000 & 11530.623 & 232.617 & 0.034 \\
\hline 31 & 4519.934 & 4800.326 & 140.083 & 285.456 & 112.182 & 3530 & 52953.421 & 353.960 & 0.025 \\
\hline 32 & 251.502 & 1015.317 & 12.557 & 372.292 & 15.324 & 550 & 4286.506 & 217.966 & 0.043 \\
\hline 33 & 411.403 & 887.137 & 14.421 & 21.398 & 14.638 & 851 & 4467.083 & 169.870 & 0.041 \\
\hline 34 & 848.390 & 1813.303 & 45.843 & 64.811 & 12.675 & 1467 & 8711.493 & 157.538 & 0.036 \\
\hline 35 & 1354.731 & 1414.213 & 111.465 & 361.860 & 21.251 & 1853 & 16048.707 & 327.895 & 0.039 \\
\hline 36 & 3498.997 & 2026.898 & 574.869 & 668.624 & 57.715 & 3830 & 55020.238 & 369.285 & 0.028 \\
\hline 37 & 780.893 & 850.901 & 2.669 & 20.302 & 15.014 & 1047 & 7047.485 & 205.739 & 0.028 \\
\hline 38 & 7438.985 & 39733.866 & 1787.119 & 2458.524 & 203.261 & 9246 & 117986.660 & 453.411 & 0.026 \\
\hline 39 & 994.093 & 41615.236 & 449.637 & 175.503 & 57.669 & 781 & 12775.468 & 556.724 & 0.033 \\
\hline 40 & 1014.401 & 859.808 & 20.355 & 28.432 & 11.597 & 1319 & 8334.103 & 147.459 & 0.039 \\
\hline Mean & 1735.564 & 5765.492 & 216.888 & 220.483 & 48.791 & 2258 & 22628.040 & 235.825 & $\mathbf{0 . 0 3 5}$ \\
\hline SD & 1760.377 & 10261.388 & 324.250 & 402.187 & 57.824 & 1988.576 & 25054.957 & 93.701 & 0.008 \\
\hline
\end{tabular}


Appendix 2: The OE, TE and AE of the 40 companies in 2005 and 2011

\begin{tabular}{|c|c|c|c|c|c|c|}
\hline \multirow[b]{2}{*}{ DMU } & \multicolumn{3}{|c|}{2010} & \multicolumn{3}{|c|}{2011} \\
\hline & OE & TE & $\mathbf{A E}$ & $\mathbf{O E}$ & TE & $\mathbf{A E}$ \\
\hline 1 & 0.451 & 0.813 & 0.555 & 0.673 & 0.780 & 0.863 \\
\hline 2 & 0.349 & 0.658 & 0.531 & 0.330 & 0.552 & 0.597 \\
\hline 3 & 0.360 & 0.529 & 0.682 & 1.000 & 1.000 & 1.000 \\
\hline 4 & 0.470 & 0.850 & 0.553 & 0.826 & 1.000 & 0.826 \\
\hline 5 & 0.325 & 0.800 & 0.406 & 0.373 & 0.687 & 0.543 \\
\hline 6 & 0.970 & 0.970 & 1.000 & 0.772 & 0.772 & 1.000 \\
\hline 7 & 0.695 & 0.984 & 0.706 & 0.632 & 0.814 & 0.776 \\
\hline 8 & 0.353 & 0.904 & 0.390 & 0.270 & 0.811 & 0.333 \\
\hline 9 & 0.813 & 0.873 & 0.931 & 0.647 & 0.791 & 0.819 \\
\hline 10 & 0.492 & 0.708 & 0.695 & 0.494 & 0.705 & 0.701 \\
\hline 11 & 0.631 & 0.807 & 0.782 & 0.424 & 0.681 & 0.622 \\
\hline 12 & 0.527 & 0.681 & 0.774 & 0.403 & 0.542 & 0.744 \\
\hline 13 & 0.381 & 0.436 & 0.874 & 0.440 & 0.530 & 0.831 \\
\hline 14 & 0.467 & 1.0001 & 0.467 & 0.667 & 1.000 & 0.667 \\
\hline 15 & 0.413 & 1.000 & 0.413 & 0.415 & 0.866 & 0.480 \\
\hline 16 & 0.637 & 0.750 & 0.849 & 0.947 & 1.000 & 0.947 \\
\hline 17 & 0.759 & 0.944 & 0.804 & 0.818 & 1.000 & 0.818 \\
\hline 18 & 1.000 & 1.000 & 1.000 & 0.800 & 0.803 & 0.997 \\
\hline 19 & 0.409 & 0.886 & 0.462 & 0.553 & 0.933 & 0.593 \\
\hline 20 & 0.538 & 0.584 & 0.921 & 0.473 & 0.554 & 0.852 \\
\hline 21 & 0.673 & 0.698 & 0.965 & 0.886 & 0.886 & 1.000 \\
\hline 22 & 0.555 & 0.829 & 0.670 & 0.440 & 0.763 & 0.577 \\
\hline 23 & 0.633 & 0.772 & 0.819 & 0.705 & 0.705 & 1.000 \\
\hline 24 & 0.376 & 0.888 & 0.423 & 0.436 & 0.957 & 0.455 \\
\hline 25 & 0.338 & 0.979 & 0.346 & 0.535 & 1.000 & 0.535 \\
\hline 26 & 0.996 & 1.000 & 0.996 & 1.000 & 1.000 & 1.000 \\
\hline 27 & 0.613 & 1.000 & 0.613 & 1.000 & 1.000 & 1.000 \\
\hline 28 & 0.514 & 1.000 & 0.514 & 0.567 & 0.821 & 0.691 \\
\hline 29 & 0.475 & 0.737 & 0.644 & 0.472 & 0.626 & 0.754 \\
\hline 30 & 1.000 & 1.000 & 1.000 & 0.400 & 0.409 & 0.979 \\
\hline 31 & 1.000 & 1.000 & 1.000 & 0.826 & 0.854 & 0.966 \\
\hline 32 & 1.000 & 1.000 & 1.000 & 1.000 & 1.000 & 1.000 \\
\hline 33 & 0.568 & 1.000 & 0.568 & 0.315 & 0.700 & 0.450 \\
\hline 34 & 0.384 & 0.889 & 0.432 & 0.388 & 0.799 & 0.486 \\
\hline 35 & 0.671 & 0.921 & 0.729 & 0.671 & 0.791 & 0.847 \\
\hline 36 & 0.565 & 0.604 & 0.934 & 0.546 & 0.624 & 0.875 \\
\hline 37 & 0.801 & 1.000 & 0.801 & 0.453 & 0.942 & 0.481 \\
\hline 38 & 1.000 & 1.000 & 1.000 & 1.000 & 1.000 & 1.000 \\
\hline 39 & 1.000 & 1.000 & 1.000 & 1.000 & 1.000 & 1.000 \\
\hline 40 & 0.404 & 0.913 & 0.443 & 0.409 & 0.695 & 0.589 \\
\hline Mean & 0.615 & 0.860 & 0.717 & 0.625 & 0.810 & 0.767 \\
\hline SD & 0.227 & 0.151 & 0.217 & 0.228 & 0.163 & 0.200 \\
\hline
\end{tabular}

